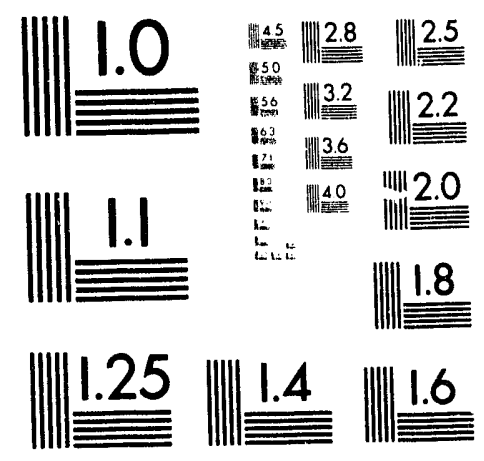



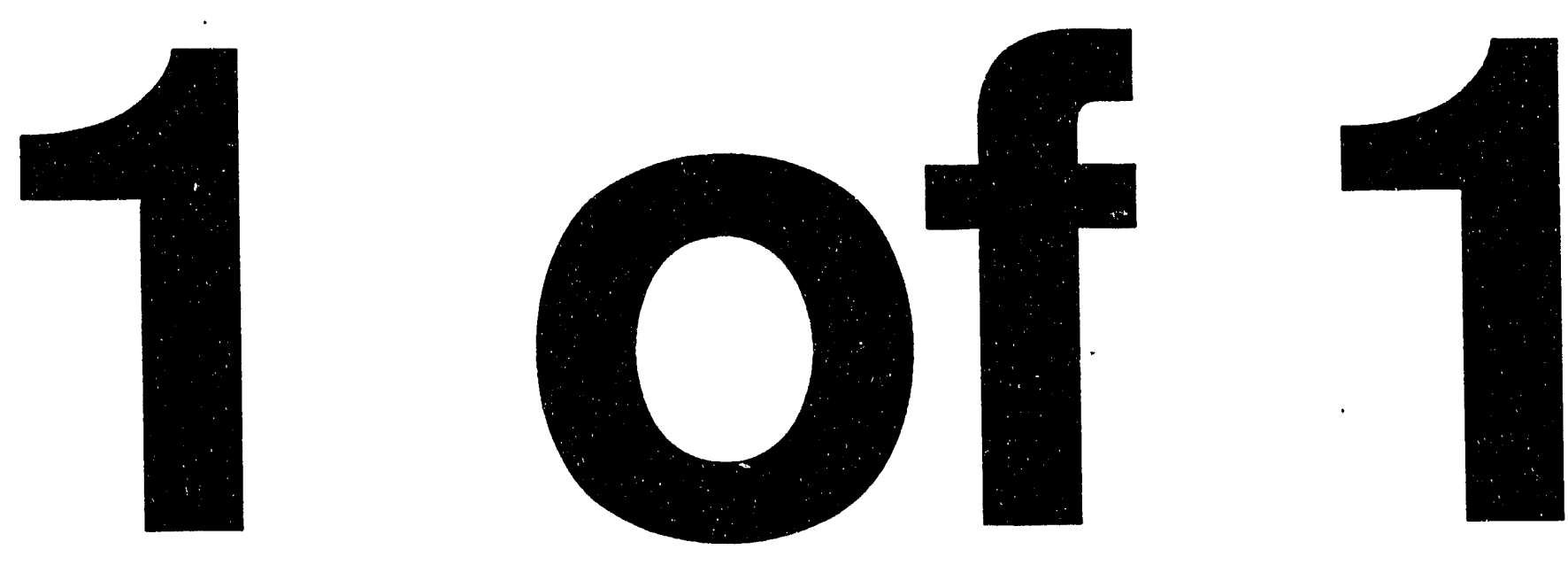
UCRL-JC- 114130

PREPRINT

\title{
Relationship Between Hydrous and Ordinary Pyrolysis
}

\author{
Alan K. Burnham
}

This paper was prepared for the NATO Advanced Study Institute on Composition Geochemistry and Conversion of Oil Shale Conference, Akcay, Turkey, July 18-31, 1993

\section{June 1993}

This is a preprint of a paper intended for publication in a journal or proceedings. Since changes may be made before publication, this preprint is made available with the understanding that it will not be cited or reproduced without the permission of the author.
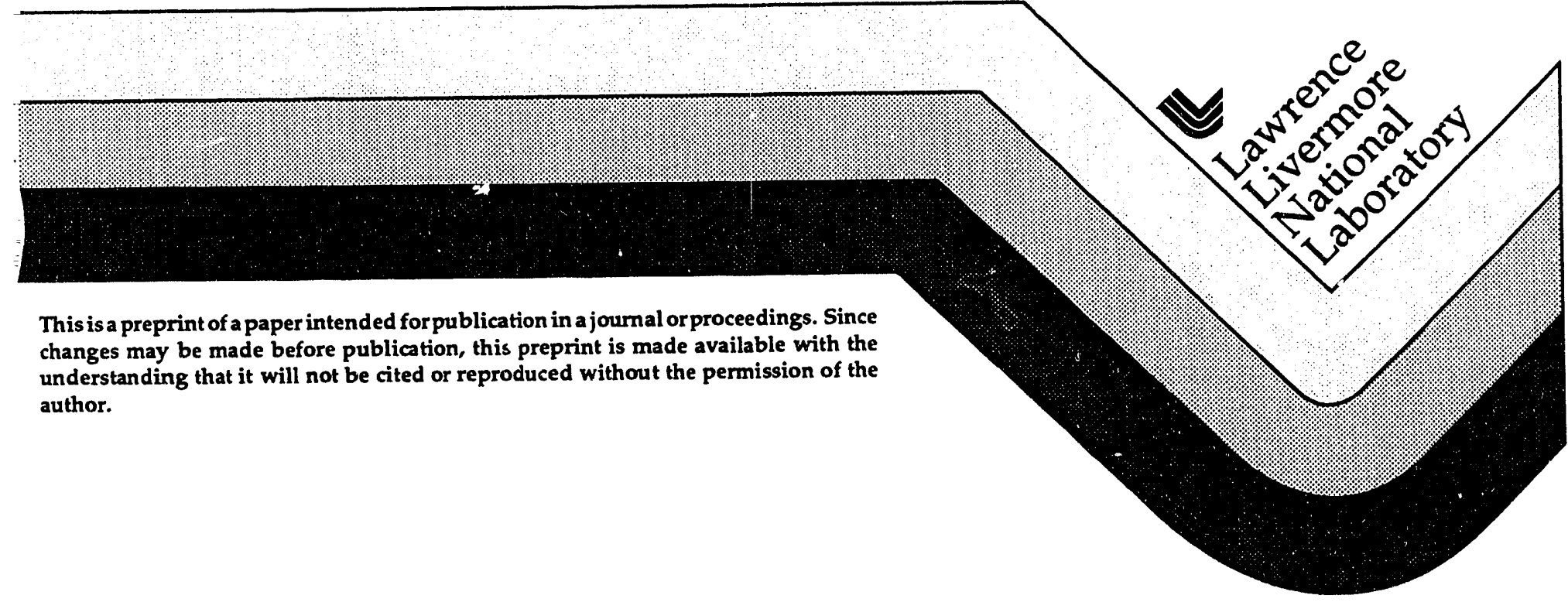


\section{DISCLAIMER}

This document was prepared as an account of work sponsored by an agency of the United States Government. Neither the United States Government nor the University of California nor any of their employees, make any warranty, express or implied, or assumes any legal liability or responsibility for the accuracy, completeness, or usefulness of any information, apparatus, product, or process disclosed, or represents that its use would not infringe privately owned rights. Reference herein to any specific commercial products, process, or service by trade name, trademark, manufacturer, or otherwise, does not necessarily constitute or imply its endorsement. recommendation, or favoring by the United States Government or the University of California. The views and opinions of authors expressed herein do not necessarily state or reflect those of the University of California, and shall not be used for advertising or product endorsement purposes. 


\title{
RELATIONSHIP BETWEEN HYDROUS AND ORDINARY PYROLYSIS
}

\author{
ALAN K. BURNHAM \\ Lawrence Livermore National Laboratory \\ Livermore, CA 94551
}

\begin{abstract}
Pyrolysis results are reviewed briefly with the intent of drawing comparisons between open, high pressure, and hydrous pyrolysis. Empirically, the degree of pyrolysis severity to form volatile products in open pyrolysis is similar to that required to form an expelled oil phase in hydrous pyrolysis. The yields of hydrocarbons from open pyrolysis are close to those from hydrous pyrolysis, but hydrous pyrolysis tends to assist the separation of hydrocarbons from polar materials. Pressure has a small but measurable affect on the generation kinetics.
\end{abstract}

\section{Introduction}

The kinetics of oil and gas generation from kerogen have application for modeling both oil shale retorts and natural petroleum formation. Oil generation kinetics have a long history, dating back to the early 20th century (McKee and Lyder, 1912). Since that time, many different experimental and data analysis techniques have been developed, with a consequent diversity of results that are difficult to reconcile. One example of an apparent discrepancy is the disagreement between kinetic parameters for oil generation derived from hydrous (e.g., Hunt et al., 1991) and rapid open-system pyrolysis (e.g., Tissot et al., 1987).

One of the major objectives of LLNL kinetics research over the past decade has been to develop an understanding of how different types of pyrolysis experiments relate to each other (Burnham and Braun, 1985; Burnham and Braun, 1990). Types of apparatus used include rapid isothermal fluidized-bed pyrolysis, nonisothermal open pyrolysis in flowing helium, nonisotherm $\hat{\imath}^{-}$. open pyrolysis in a self-generated atmosphere, hydrous highpressure pyrolysis in a closed system, and non-hydrous high-pressure pyrolysis in a closed . system. During the same time, we developed more efficient data analysis procedures to compare various models, such as pseudo-nth-order and activation energy distribution kinetics (Braun and Burnham, 1987; Burnham et al., 1987).

The purpose of this paper is to critically evaluate available oil and gas kinetic results from the past ten years in an attempt to more clearly establish the similarities and differences of hydrous and non-hydrous techniques. The paper draws primarily on published data, although some re-analysis is undertaken. Only enough of the literature is used to establish what appear to be general relationships.

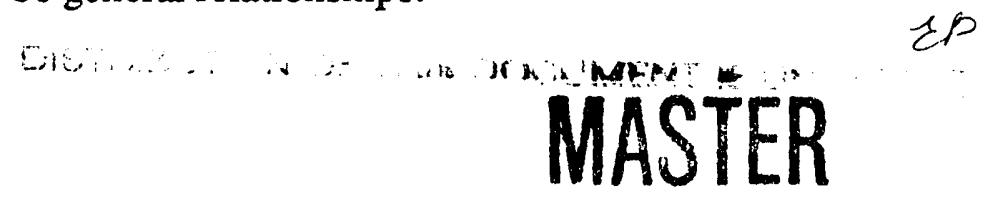




\section{A Simple Reference Frame for Chemical Kinetics}

A first-order reaction is described by the equation

$$
\mathrm{dx} / \mathrm{dt}=\mathrm{k}(1-\mathrm{x})
$$

where $\mathrm{x}$ is the fraction reacted and $\mathrm{k}$ is the rate constant at a given temperature. The rate constant is actually temperature ciependent, and the dependence is given by the Arrhenius law, $k=A$ e-E/RT, where $E$ is the activation energy, $A$ is the frequency factor, $R$ is the gas constant, $\mathrm{T}$ is the absolute temperature.

At a fixed temperature, Eq (1) can be easily integrated, giving

$$
\mathrm{x}=1-\mathrm{e}^{-\mathrm{kt}} \text {. }
$$

Plotting $\ln (1-x)$ vs $t$ gives a straight line with a slope of $k$. Determining $k$ at various $T$, then plotting $\ln (k)$ versus $1 / T$ gives a slope of $-E / R$ and an intercept of $\ln (A)$.

Both $A$ and $E$ of a single first order reaction can be determined from a single experiment where $T$ increases linearly with time (constant heating rate). An approximate solution for the resulting exponential integral gives

$$
\mathrm{dx} / \mathrm{dt}=\mathrm{A} \exp [-\mathrm{E} / \mathrm{RT}-\mathrm{ART} 2 / \mathrm{EH} \cdot(1-2 \mathrm{RT} / \mathrm{E}) \cdot \exp (-\mathrm{E} / \mathrm{RT})]
$$

and

$$
x=1-\exp [-A R T 2 / E H \cdot(1-2 R T / E) \cdot \exp (-E / R T)]
$$

where $\mathrm{H}$ is the heating rate. These equations, as well as other integration methods (Braun and Burnham, 1987), can be used in a variety of ways to deduce $A$ and $E$. If constant heating rate experiments are conducted at more than one heating rate, $\mathrm{A}$ and $\mathrm{E}$ can be determined from the shift in $\mathrm{T}_{\max }$, the temperature of maximum reaction rate, via

$$
\ln \left(\mathrm{H} / \mathrm{RT}_{\max }{ }^{2}\right)=\ln (\mathrm{A} / \mathrm{E})-\mathrm{E} / \mathrm{RT}_{\max }
$$

Unfortunately, the thermal decomposition of most kerogens is not described by a first order reaction, as shown schematically in Figure 1. A concave downward from a first order decay could be attributed to a variety of mechanisms, including a reaction order less than one or a serial reaction aspect of the decomposition. This corresponds to a narrower peak at a constant heating rate. A concave upward deviation from the first-order curve can be attributed to either a reaction order greater than 1 or multiple, overlapping reactions. 

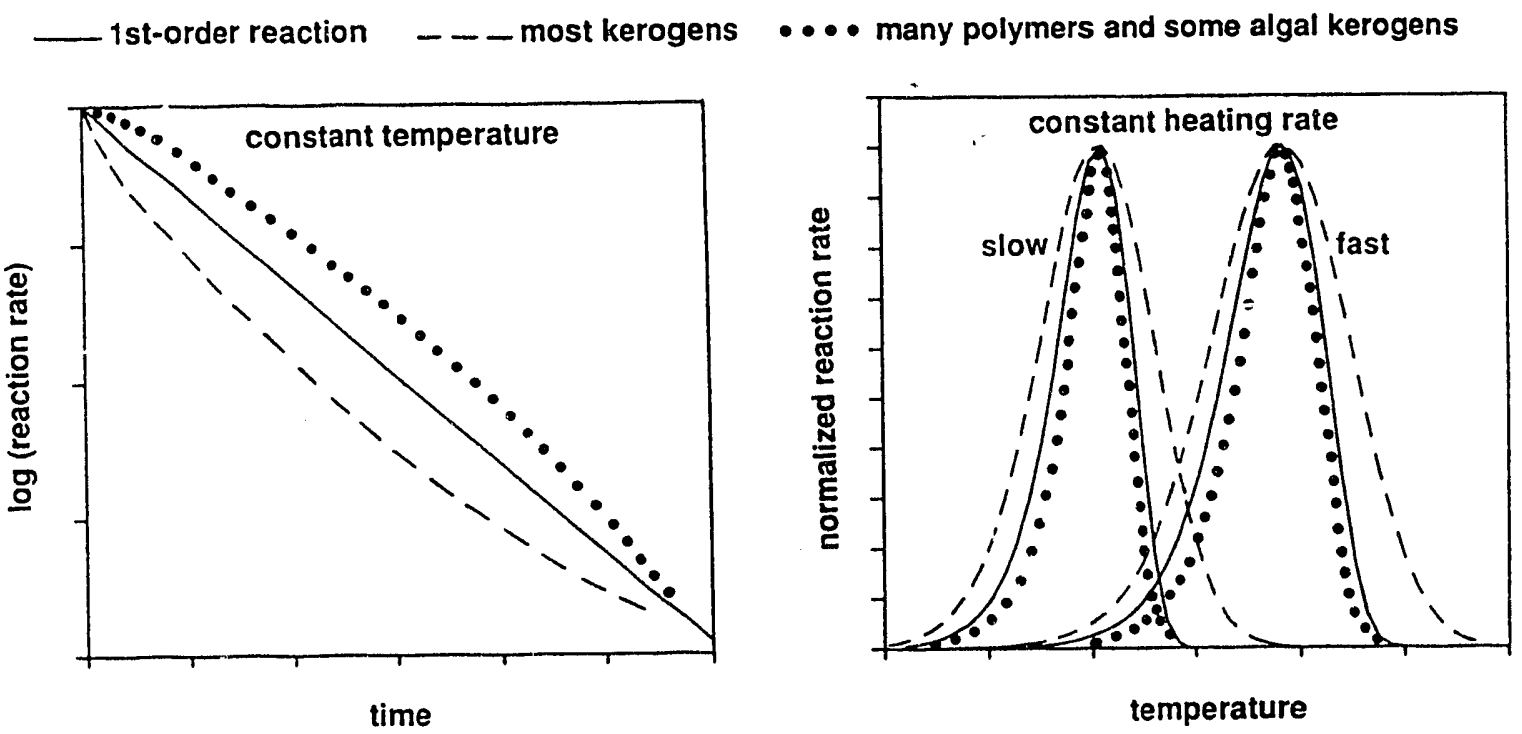

Figure 1. Summary of kerogen pyrolysis characteristics for isothermal and nonisothermal pyrolysis conditions.

\section{Atmospheric Pressure Non-Hydrous Pyrolysis}

It was noted many years ago that cil generation is normally preceded by generation of a non-volatile bitumen, which subsequently breaks down into oil. This was first explicitly taken into account in a kinetic analysis to my knowledge by McKee and Lyder (1921), and it was clearly present in the classic work on Green River sh.je of Hubbard and Robinson (1950). As a second issue, it has been demonstrated for many kerogens that the composition of volatile oil and gas products is not constant throughout the generation process, suggesting that different reactions are occurring. These two observations have led to two commonly applied models:

$$
\begin{array}{ll}
\text { serial reaction model } & A-B=C \\
\text { parallel reaction model } & A \geq C
\end{array}
$$

In these equations, A represents kerogen; B, bitumen; and C, oil and gas. Unfortunately, it is not widely appreciated that they are not mutually exclusive, and neither by itself is truly adequate.

The inadequacy of the serial reaction mechanism for most kerogens can be shown quite simply in theory: a serial reaction by its very nature must have an induction time for the appearance of product. As a practical matter, all isothermal experiments involving solid decomposition reactions suffer from a finite heating time, which can be confused with a 
chemical induction time. Braun and Rothman (1975), in their reanalysis of Hubbard and Robinson's data, attempted to take the heatup time into account by assuming that the initial time could be shifted, but this is probably inadequate. More recent experiments with small samples (Wallman et al., 1981; Burnham et al., 1989, Bar et al., 1988; Klomp and Wright, 1990) have shown that most kerogens have their maximum rate of hydrocarbon production as soon as the sample reaches temperature. Furthermore, most deviations from first-order generation kinetics are just the opposite of that required for a serial reaction, as summarized in Figure 1, indicating either a reaction order greater than one or multiple generation reactions.

The serial reaction mechanism has additional shortcomings. Braun and Rothman (1975) fitted only the appearance of oil to determine both rate constants ( $\mathrm{k} 1$ and $\mathrm{k} 2)$ in the serial reaction model. They reached a plausible conclusion that the activation energy for bitumen generation is less than that of oil generation. However, this result leads to an interesting question: does the bitumen generation reaction become rate limiting at high temperatures because of its weak temperature dependence? Subsequent fluidized bed experiments indicated not (Wallman et al., 1981; Burnham et al., 1989).

An additional problem with the serial reaction model for Colorado and Kentucky oil shale was found by Miknis et al. (1987). The maximum conversion of organic matter to bitumen is related to the ratio of $\mathrm{k} 1$ and $\mathrm{k} 2$, and the temperature dependence of the maximum bitumen yield gives the relative activation energies of $k 1$ and $k 2$. The maximum bitumen yield increased with temperature for both shales, indicating that the activation energy for bitumen formation must be higher than that for oil generation, just the opposite of what one would expect. Although the issue has not been resolved satisfactorily, it is noteworthy that Ziegel and Gorman (1980) found a better fit to Hubbard and Robinson's bitumen and oil data with an alternate pathway model:

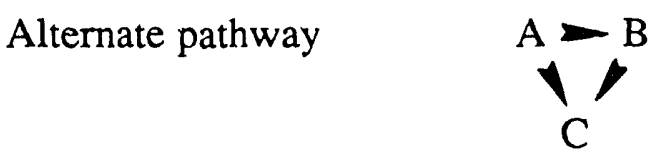

This allows the maximum rate of oil generation to occur at the beginning of pyrolysis while still allowing part of the material to go through a bitumen intermediate.

Nonisothermal experiments overcome two disadvantages of isothermal experiments: the finite heat-up time mentioned earlier and the difficulty in studying the entire extent of reaction over a very wide temperature range. Early nonisothermal experiments in the geochemical community suffered from poor temperature measurements, but over the past few years, careful measurements have yielded close results at several laboratories (Schaefer et al., 1990; Braun et al., 1991; Sundararaman et al., 1992; Jarvie, 1992).

An extensive database of constant heating rate experiments has established that generation of oil and gas from Green River Mahogany-zone oil shale is described fairly well by a single first-order reaction. However, some Green River and other algal kerogen samples have a narrower reaction profile than calculated for a first-order reaction using the activation energy determined from the shift in $\mathrm{T}_{\max }$ with heating rate. This is consistent to some extent with a serial reaction, but other polymer decomposition theories may be more appropriate. While the appropriate kinetic model for these kerogens in still in question, a 
correlation between a narrow reaction profile and a concave downward deviation from a first-order decay is well established.

Most kerogens, which are typically marine in origin, have a broader reaction profile than is calculated from the activation energy determined from the shift in $T_{\max }$ with heating rate. Numerical studies have shown that the activatio' 1 energy determined from this shift is still valid for a a parallel reaction model having a dis ribution of activation energies (Braun and Burnham, 1987). Although an nth-order reaction model also works well, the wider profile width would seem to be more properly described by a reactivity distribution because a reactivity distribution is consistent with the heterogeneity of kerogen and with the changing composition of products versus the extent of conversion.

A possible structural interpretation of these kinetic observations is given in Figure 2. Most kerogens may have some weak links (W) that can break and form soluble moieties. However, oil is formed by breaking carbon bonds, and the structure is sufficiently branched that breaking any particular carbon bond will form oil. In contrast, algal kerogens having an induction period must require more than one carbon bond to break to form a fragment small enough to be classified as oil. A single broken bond may lead to a soluble species. Such kine ic behavior is similar to linear polymers.

- Serial reactions

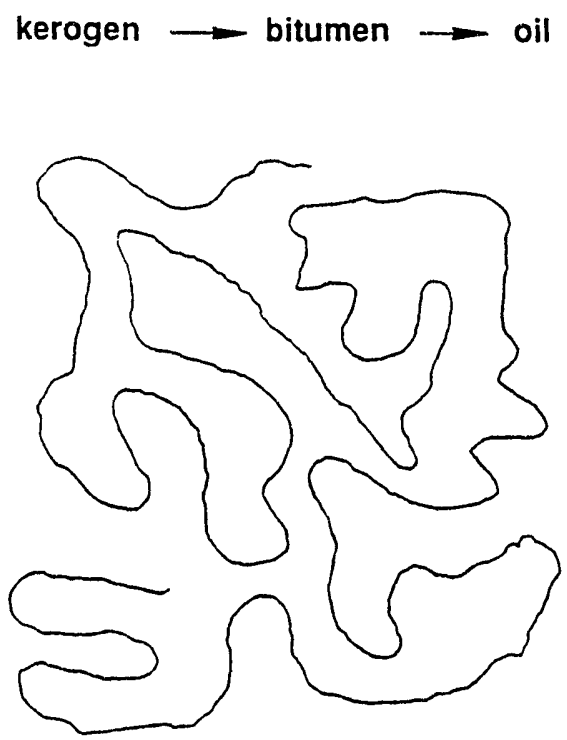

\section{- Alternate pathways}

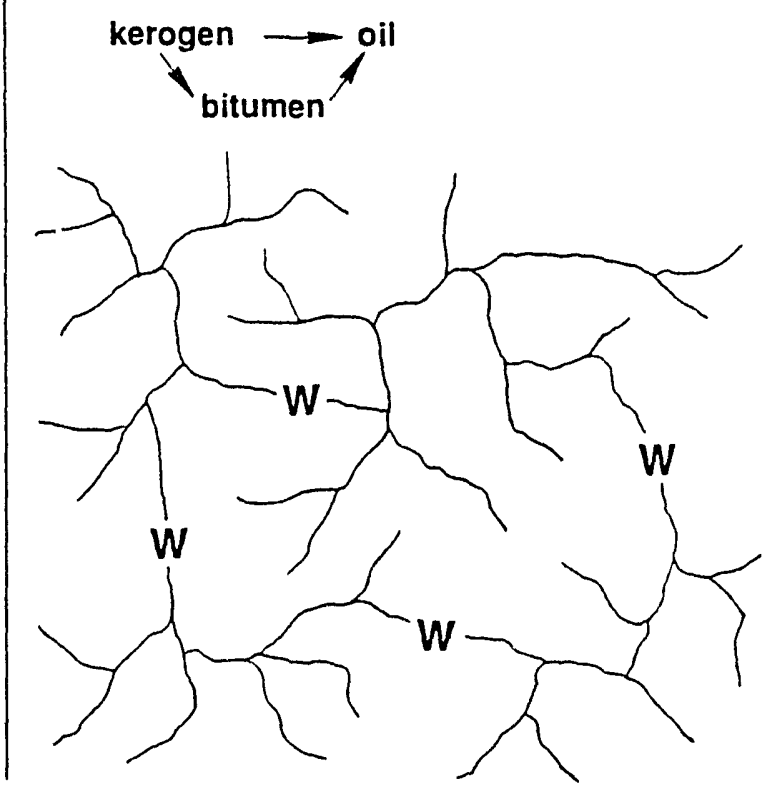

Figure 2. Schematic representation of kerogen structures based on kinetic behavior 


\section{High Pressure Non-Hydrous Pyrolysis Experiments}

High pressure experiments are of interest for a variety of applications, including some oil shale extraction schemes and for natural generation of petroleum. The role of pressure has been controversial, with different workers coming to different conclusions about its importance. Ty pes of high pressure apparatus include sealed, constani volume autoclaves, sealed glass capillaries, pressured gold capsules, and pressurized open systems.

A first step to understand the role of pressure is to realize that not all workers measure equivalent properties, and some experiments are affected by mass transfer phenomena. Burnham and Singleton (1983) noted that pressure delays the release of oil from a pressurized open reactor, but Burnham and Braun (1985) later showed that most of the effect can be attributed to the influence of pressure on oil vaporization, not its formation.

Sch enk and Horsfield (1993) determined very similar kinetics by pyrolysis of whole rocks in an open system and pyrolysis of a the corresponding kerogen in a sealed glass tubes. This is consistent with the result of Freund et al. (1992), who found a small but measurable affect of pressure on generation rate, but inconsistent with the results of Price and Wenger (1992), who report that pressure has a profound retarding effect on oil generation. Freund examined several types of reactor configurations to ensure that no artifacts could influence the conclusions, so his results are more convincing. He interpreted his results in terms of an activation volume and obtained values of about 30 $\mathrm{cm} 3 / \mathrm{mol}$, about what one would expect based on polymerization experiments.

\section{Hydrous Pyrolysis}

Lewan (Lewan et al., 1979; Lewan, 1985) has promoted the hydrous pyrolysis technique as one that is more representative of natural maturation. In hydrous pyrolysis, as strictly defined, there is enough liquid water to cover the sample, and an expelled hydrocarbon phase is found at the top of the water at the end of the experiment. The expelled hydrocarbon phase is said to be much more like natural petroleum than either the whole hydrous pyrolysis extract or pyrolysates obtained from non-hydrous pyrolysis.

My experience indicates that the differences between hydrous and non-hydrous pyrolysis, though real, have been overstated. The original paper by Lewan et al. (1979) compares the composition of expelled pyrolysates to Fischer assay oil composition and notes that they are significantly different. However, it has been well established that the composition of oil from Fischer Assay-like experiments depends on both the heating rate and pressure (Burnham and Singleton, 1983). With no added water, the pyrolysate produced at $1{ }^{\circ} \mathrm{C} / \mathrm{h}$ and 27 bar has little alkerie content and substantially reduced polar content, making it much more like the expelled phase and natural petroleum. The $1{ }^{\circ} \mathrm{C} / \mathrm{h}$ heating rate causes the oil to be formed at rnughly the same temperature as in hydrous pyrolysis for $72 \mathrm{~h}$.

A more detailed comparison between hydrous pyrolysis fractions and modified Fischer assay pyrolysates from a Posidonia shale is given in Tables 1 and 2 (from Burnham, 1990). The hydrous pyrolysates were generated by Marzi (1989) and obtained from the KFA. The open system pyrolysate produced in a self-purging reactor at $2{ }^{\circ} \mathrm{C} / \mathrm{h}$ (Burnham, 1991) is fairly close to the expelled oil in aromatic content and elemental composition. The absolute yields of individual compounds and hydrocarbon groups is also quite similar. The 


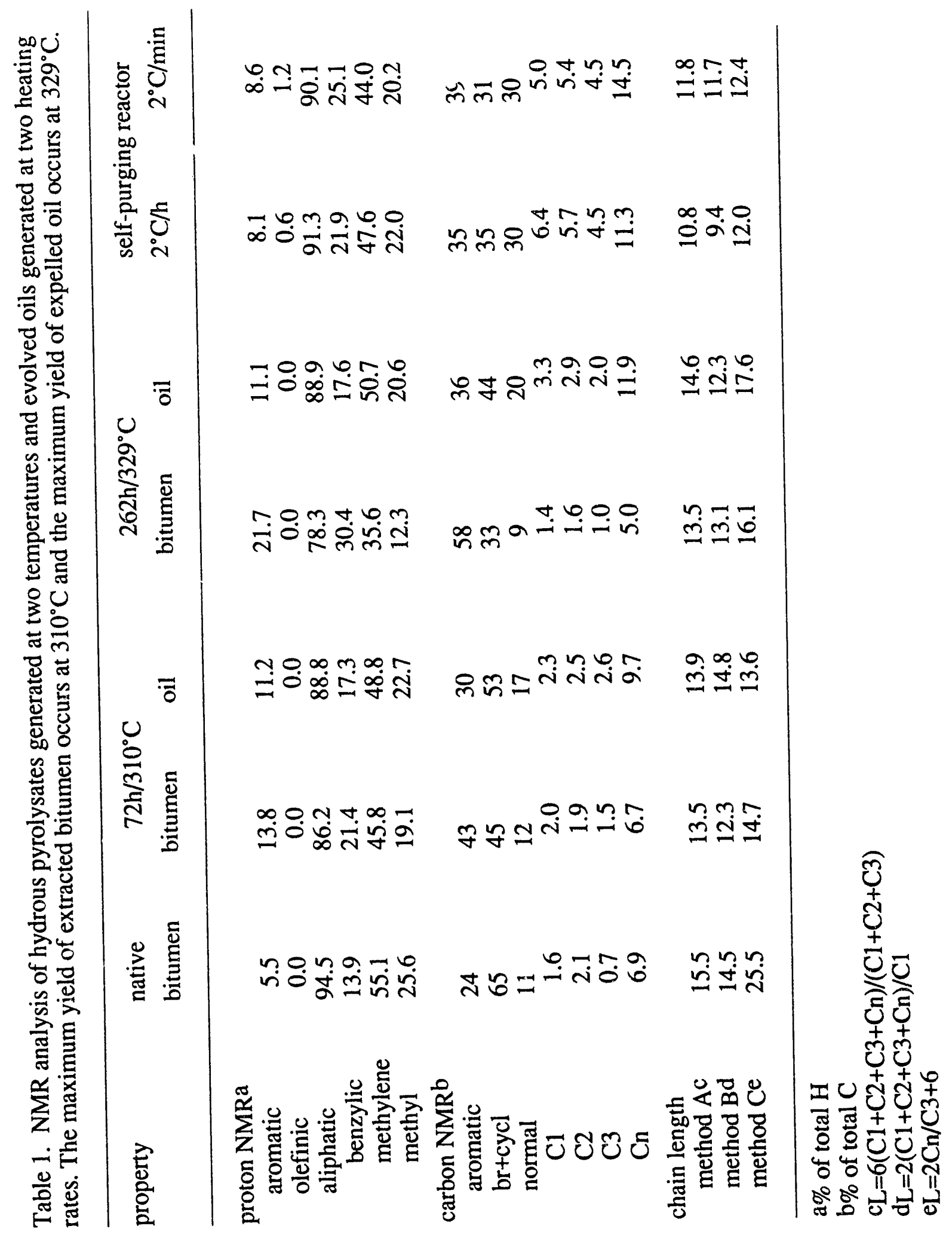


difference in chain length and total normal alkane yield may be due to the near absence of $\mathrm{C}_{6}-\mathrm{C}_{9}$ in the hydrous pyrolysate, possibly due to handling. The overall similarity suggests that much of the earlier difference between hydrous and open system pyrolysis products is due to temperature, not pressure or water.

Table 2. Gas chromatographic analysis of expelled and evolved oils. The expelled oil represents conditions for maximum oil yield from hydrous pyrolysis.

\begin{tabular}{|c|c|c|}
\hline \multirow{2}{*}{ Property } & Expelled oil & Evolved oils \\
\hline & $262 \mathrm{~h} / 329^{\circ} \mathrm{C}$ & $2^{\circ} \mathrm{C} / \mathrm{h} \quad 2^{\circ} \mathrm{C} / \mathrm{min}$ \\
\hline
\end{tabular}

oil concentration, \%:

$\begin{array}{llll}\text { pristane } & 0.19 & 0.17 & 0.09 \\ \text { pris-1-ene } & - & 0.02 & 0.04 \\ \text { phytane } & 0.08 & 0.09 & 0.06 \\ \text { n-C17 ane } & 0.36 & 0.39 & 0.23 \\ 1-C_{17} \text { ene } & (.03)^{\mathrm{a}} & 0.10 & 0.13 \\ \text { n-C18 ane } & 0.30 & 0.29 & 0.18 \\ 1-C_{18} \text { ene } & (.02)^{\mathrm{a}} & 0.05 & 0.07 \\ \text { C7-C31 anes } & 5.0 & 7.3 & 4.5 \\ \text { C7-C31 enes } & (.4)^{\mathrm{a}} & 1.5 & 1.9\end{array}$

alkene + alkane ratios:

$\begin{array}{llll}\mathrm{pr} / \mathrm{ph} & 2.3 & 2.2 & 1.9 \\ \mathrm{pr} / \mathrm{n}-\mathrm{C}_{17} & 0.57 & 0.34 & 0.25 \\ \mathrm{ph} / \mathrm{n}-\mathrm{C}_{18} & 0.30 & 0.27 & 0.26\end{array}$

alkene + alkane yields, $\mathrm{mg} / \mathrm{g}$ TOC:

$\begin{array}{llll}\text { pristane } & 0.64 & 0.76 & 0.60 \\ \text { phytane } & 0.28 & 0.35 & 0.31 \\ \text { n-C17 } & 1.2 & 1.9 & 1.6 \\ \text { n-C18 } & 1.0 & 1.3 & 1.2 \\ \text { C7-C } 31 & 17 & 34 & 31 \\ \text { total normalb } & 68 & 116 & 146\end{array}$

aconsidered to be interfering compounds because proton

NMR detected essentially no alkenes

bfrom 13 C NMR 
Another difference between hydrous and open pyrolysis is the yields from the two types of experiments. Table 3 compares the bitumen and expelled oil yields for a variety of samples to the hydrogen index of the same or similar material. The expelled oil yields are always significantly lower than the hydrogen index. Additional information on gas yields indicates that most of the difference is related to differences in liquid yields. Given that slower open system experiments produce an oil more similar to the expelled oil due to the coking of polar material in the oil, it appears that another part of the difference between hydrous and open pyrolysis is that much of the polar fraction in hydrous pyrolysis remains absorbed on the rock, while it is volatilized in the open system experiments.

Table 3. Maximum yields of extracted bitumen and expelled oil (mg product/g TOC) along with TOC and Rock-Eval HI

\begin{tabular}{lrrccc}
\hline Source rock & TOC & HI & max bit & max oil & reference \\
\hline Green River & 10.6 & 877 & 319 & 575 & Peters (1986) \\
Monterey & 4.5 & 501 & 204 & 319 & $"$ \\
Monterey & 11.6 & 615 & 249 & 285 & " \\
Woodford & 12.1 & 588 & 388 & 264 & Lewan (1985, 1989) \\
Phosphoria & 20.9 & 644 & 911 & 313 & " \\
Phosphoria & 22.8 & & & 380 & Winters et al. (1981) \\
Kimmeridge & 11.2 & & & 362 & " \\
Kimmeridge & 25.2 & & & 334 & Vallejos (1990) \\
La Luna & 4.2 & 650 & 607 & 440 & Marzi (1989) \\
Posidonia & 12.1 & 660 & 347 & 331 & \\
\hline
\end{tabular}

Even though the differences may have been overstated, there do seem to be some real effects due to water. Lewan (1992) has reported otherwise identical experiments with no added water and enough water to form a liquid phase covering the sample. He finds that in the early stages, hydrous and ordinary pyrolysis produce about the same about of pyrolysate. At higher temperature, hydrous pyrolysis produces more oil plus bitumen, but most of the difference is in bitumen extracted from the rock in the hydrous case.

Apparently, water inhibits the coking reactions that cause major yield loss in ordinary sealed vessel pyrolysis. The hydrous pyrolysis oil-plus-bitumen yields are fairly similar to the yield in open pyrolysis, indicating that the inhibiting effect of water on coking is comparable to that of escape by volatilization. Le'van also found that water caused a substantially greater generation of $\mathrm{CO}_{2}$, suggesting that it is acting as both an oxidizer and source of hydrogen in its reaction with kerogen.

Given the differences in product yields and composition, it is not obvious how the rate parameters of hydrous and non-hydrous experiments should compare. Kinetics in the literature for hydrous pyrolysis experiments have generally been based on a first-order assumption using expelled oil yields as a function of temperature at a single time. Unlike 
the fairly narrow range of activation energies found from accurate open pyrolysis experiments, typically 50 to $56 \mathrm{kcal} / \mathrm{mol}$, reported activation energies for hydrous pyiolysis range from the mid- $30 \mathrm{kcal} / \mathrm{mol}$ range to the low $-60 \mathrm{kcal} / \mathrm{mol} \mathrm{range}$.

After numerous comparisons of hydrous and open system kinetics, evidence appears strong that the wide range of activation energies from hydrous pyrolysis is due to a misapplication of first-order kinetics. Burnham (1991) showed that first-order hydrous nyrolysis kinetics predict fairly well the formation of volatile oil in open-system pyrolysis where the heating rate is such $\left(1\right.$ to $\left.2^{\circ} \mathrm{C} / \mathrm{h}\right)$ that the temperature of oil formation is similar to that in hydrous pyrolysis. However, most of these first-order kinetic parameters predict that oil is formed at a much higher temperature than is observed for higher heating rates. In contrast, kinetic parameters derived from open pyrolysis using activation energy distribution models accurately predict the timing of expelled oii in hydrous pyrolysis as well as the formation of volatile oil in open pyrolysis over a wide temperature range. A comparison is shown for four samples in Figure 3.
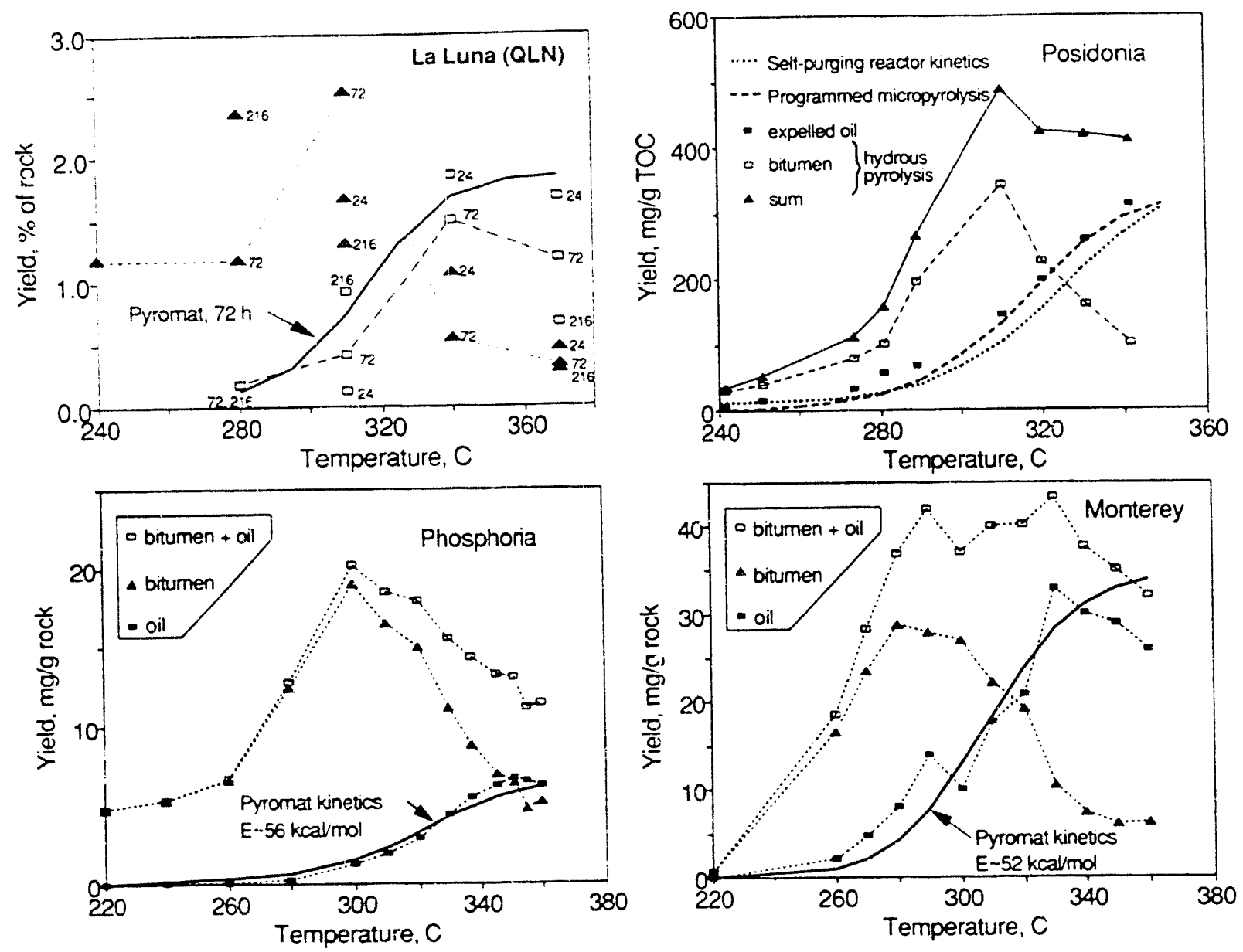

Figure 3. Comparison of hydrous pyrolysis yields with open system kinetics. The open system yields have been scaled to the maximum expelled oil yield. The numbers by the La Luna data points indicate the time of pyroiysis in nours. 
The Monterey shale deserves special attention because it has the largest discrepancy between reported activation energies for hydrous and open pyrolysis. Tabular hydrous pyrolysis yield data supplied by Ken Peters (Baskin and Peters, 1992) was analyzed using the assumption that the appearance of both bitumen and expelled oil can be described by a first-order reaction. The results are shown in Figure 4. Even though the noise in the oil generation data is substantial and there is uncertainty in the maximum yield of both oil and bitumen, it is clear that the first-order activation energy for oil generation is less than that of bitumen, counter to what one would expect. The oil generation activation energy is similar to that reported by Lewan for hydrous pyrolysis of a different Monterey sample.

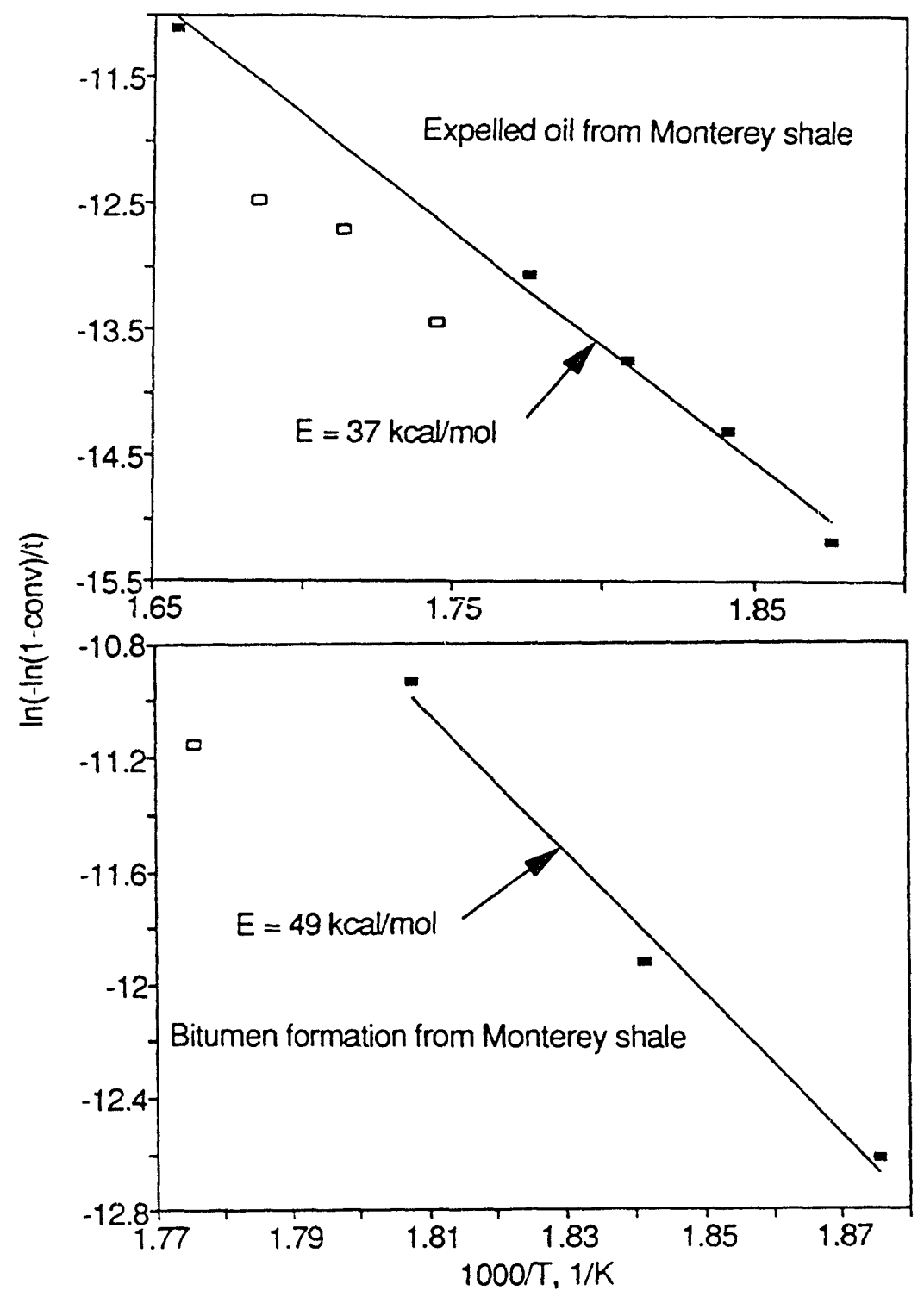

Figuic 4. Anhenius plots for bitumen and expelled oil formation from Monterey shale, using data from Baskin and Peters (1992). 
The problem with these kinetic parameters is readily apparent if viewed at both laboratory and geologic heating rates, as shown in Figure 5. If the reactions are assumed to be independent and extrapolated to a geological heating rate, one finds that oil generation is predicted to occur below $100^{\circ} \mathrm{C}$, despite geologic observations to the contrary (Jarvie, 1991). If one requires the oil to form from bitumen, one is forced to justify and use a serial reaction model, not a first-order model, to analyze the expelled oil data. One also needs to explain away the contradiction of the lack of an induction time in the isothermal open system experiments.

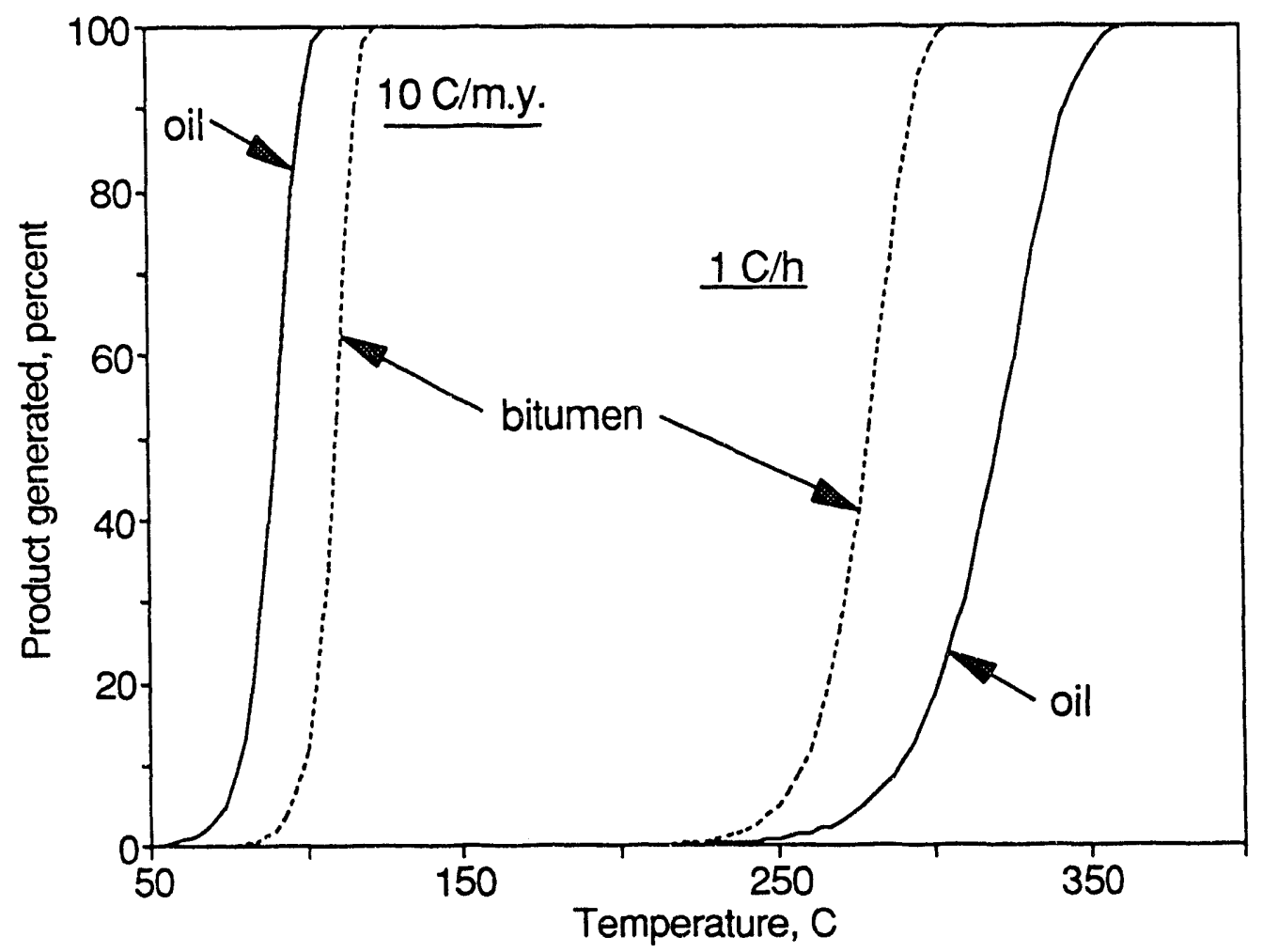

Figure 5. Extrapolation of Monterey kinetics to geological heating rates.

Open-system kinetic parameters for a similar Monterey sample were measured with a Pyromat instrument. In agreement with others (Tissot et al., 1987; Jarvie, 1991), we obtained a principal activation energy in the low $50 \mathrm{kcal} / \mathrm{mol}$ range. Oil generation was calculated at hydrous pyrolysis conditions with these kinetics, and the calculated temperature range agreed well with the temperature range over which oil is expelled during hydrous pyrolysis (Figure 3 ). This is the sixth such favorable comparison made (following Green River, Woodford, Phosporia, Posidonia, and La Luna samples), indicating that it is not a fluke. Furthermore, Schenk and Horsfield (1993) recently reached a similar conclusion when comparing open and sealed-tube pyrolysis. While the mechanistic interpretation is still unclear, there now seems to be little doubt that the low activation energies reported by Lewan (1985) and Hunt et al. (1991) are artifacts of an improper kinetic analysis. 
Is it possible to analyze hydrous pyrolysis data with activation energy distribution models? There are two problems. First, either multipie heating times at various temperatures or two series of constant heating rate experiments quenched at various temperatures are required for experiments in which expelled oil is measured separately. No such data sets with adequate accuracy exist. Second, the expected deviation from first-order behavior is such that oil generation should persist longer than extrapolated from initial production rate, but oil destruction reactions that occur in the closed system probably mask this persistence. It is questionable whether it is possible to adequately test the expelled-oil first-order kinetic hypothesis. On the other hand. Burnham (1990) demonstrated that disappearance of S2 potential (both before and after extraction) in the residues of hydrous pyrolysis requires an activation energy distribution. The latter are shown in Figure 6.
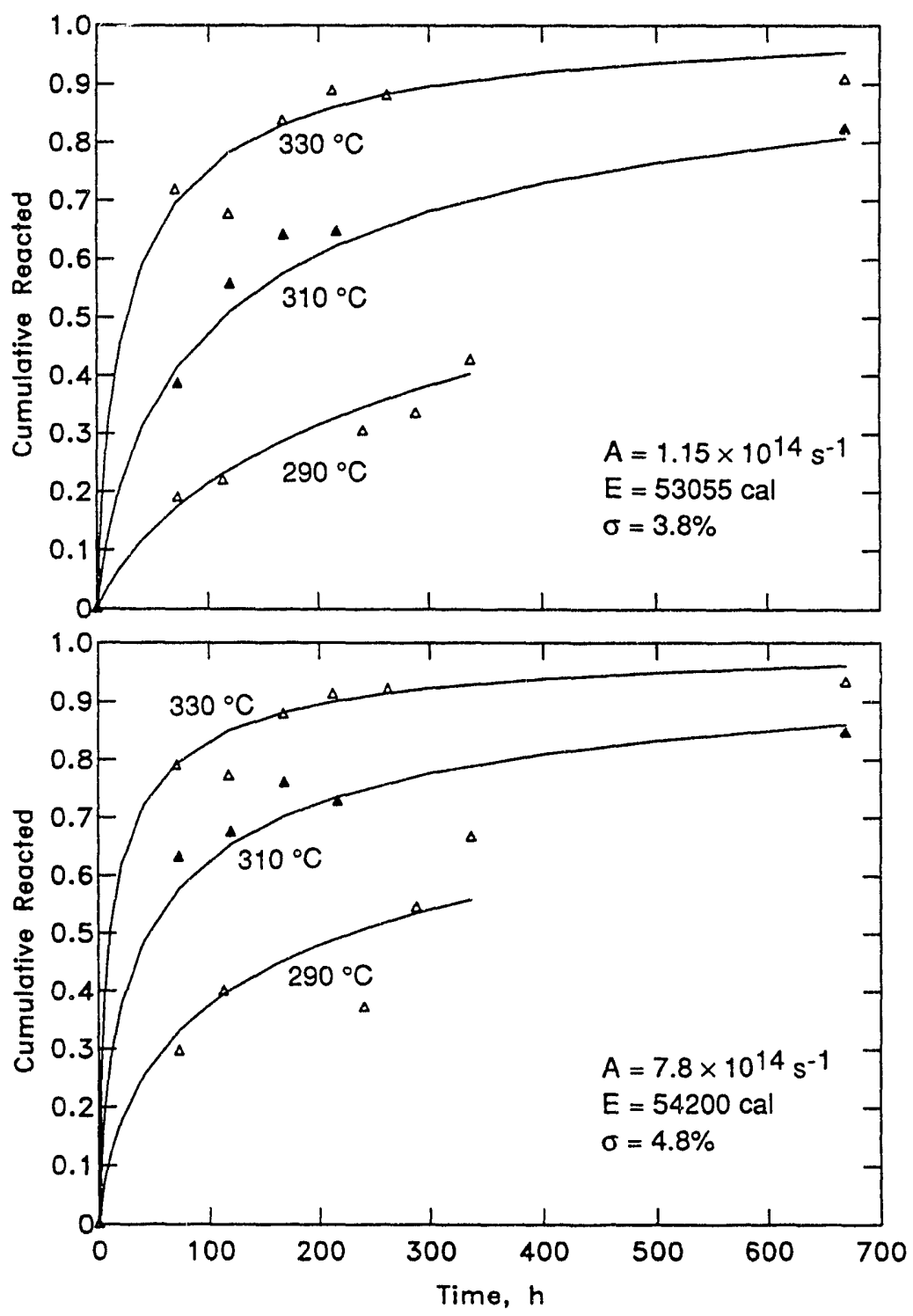

Figure 6. Kinetic analysis of remaining Rock-Eval potential, before and after extraction, with a Gaussian activation energy model. 
It cannot be merely another coincidence that the kinetics of S2 disappearance before extraction are virtually identical to those determined from formation of volatile hydrocarbons in open pyrolysis. It is also encouraging that the S2 kinetics extrapolate fairly well to a geological heating rate (Figure 7). In addition, Castelli et al. (1990) generated enough data for total pyrolysate yield to demonstrate that an activation energy distribution is required and derived a mean activation energy of about $55 \mathrm{kcal} / \mathrm{mol}$.

\section{Limitations of Parallel Reaction Models}

While the need for some type of distributed reactivity model for most kerogens is clear, it is less clear that a simple parallel reaction model is adequate. Early support for a parallel reaction model over a single reaction model came from the observation that the $T_{\max }$ of the remaining material increased as a function of maturity as was observed for geological maturation of type II and type III kerogens. However, on closer inspection, the parallel reaction does not match the precise natural maturation trend. One of the properties of a parallel reaction model is that the $T_{\max }$ of the remaining material does not change until a significant fraction of the potential is generated. In contrast, geologic maturation causes a $10-15^{\circ} \mathrm{C}$ increase in $T_{\max }$ before significant generation occurs. Burnham and Dahl (1993) found for the North Viking Graben that $I_{\text {max }}$ increases steadily with depth, but significant oil generation does not occur until $\mathrm{T}_{\max }$ has increased from about $420^{\circ} \mathrm{C}$ to between 430 and $435^{\circ} \mathrm{C}$. Further discrepancies between natural maturation and parallel reaction model calculations have been found for the Bakken shale (Sweeney et al., 1992) and San Juan basin coals (Reynolds and Burnham, 1993).

One can understand the source of the problem when one considers that kerogen undergoes considerable changes during maturation, particularly the elimination of oxygen, prior to generating significant hydrocarbons. Why this would cause the hydrocarbon $T_{\max }$ to increase is not certain, but it has been proposed (Solomon, 1992) that elimination of oxygen substituents from an aromatic ring increases the energy required to break the bond between a hydrocarbon substituent and the same aromatic ring. This would cause $T_{\max }$ to increase during early maturation as the oxygen is eliminated.

The importance of oxygen in the hydrocarbon generation mechanism has other implications. Our earlier comparisons between hydrous and open-system pyrolysis for the La Luna formation indicated that carbon dioxide is generated more easily during hydrous pyrolysis than predicted by open-system pyrolysis kinetics (Burnham et al., 1992). As a result, more oxygen is still present in the kerogen during the hydrocarbon generation phase when very immature samples undergo open-system pyrolysis than when the samples reach the hydrocarbon generation phase in nature. In addition, the oxygen appears to form refractory cross-links during open pyrolysis (Reynolds and Burnham, 1993).

Because of the unforeseen ways in which these reactions might affect the apparent activation energy, we have tentatively concluded that open-system kinetics from highly immature source rock samples are not reliable predictors of natural maturation. We found in the past (Burnham et al., 1989) that very immature coal samples appeared to have higher mean activation energies that those in the incipient oil generation phase. While a subsequent study of the San Juan basin coals (Reynolds and Burnham, 1993) saw less of a trend, very high ( $<60 \mathrm{kcal} / \mathrm{mol})$ mean activation energies have been observed for highoxygen Monterey and Norwegian samples. The evidence is not as strong as desired, but it 


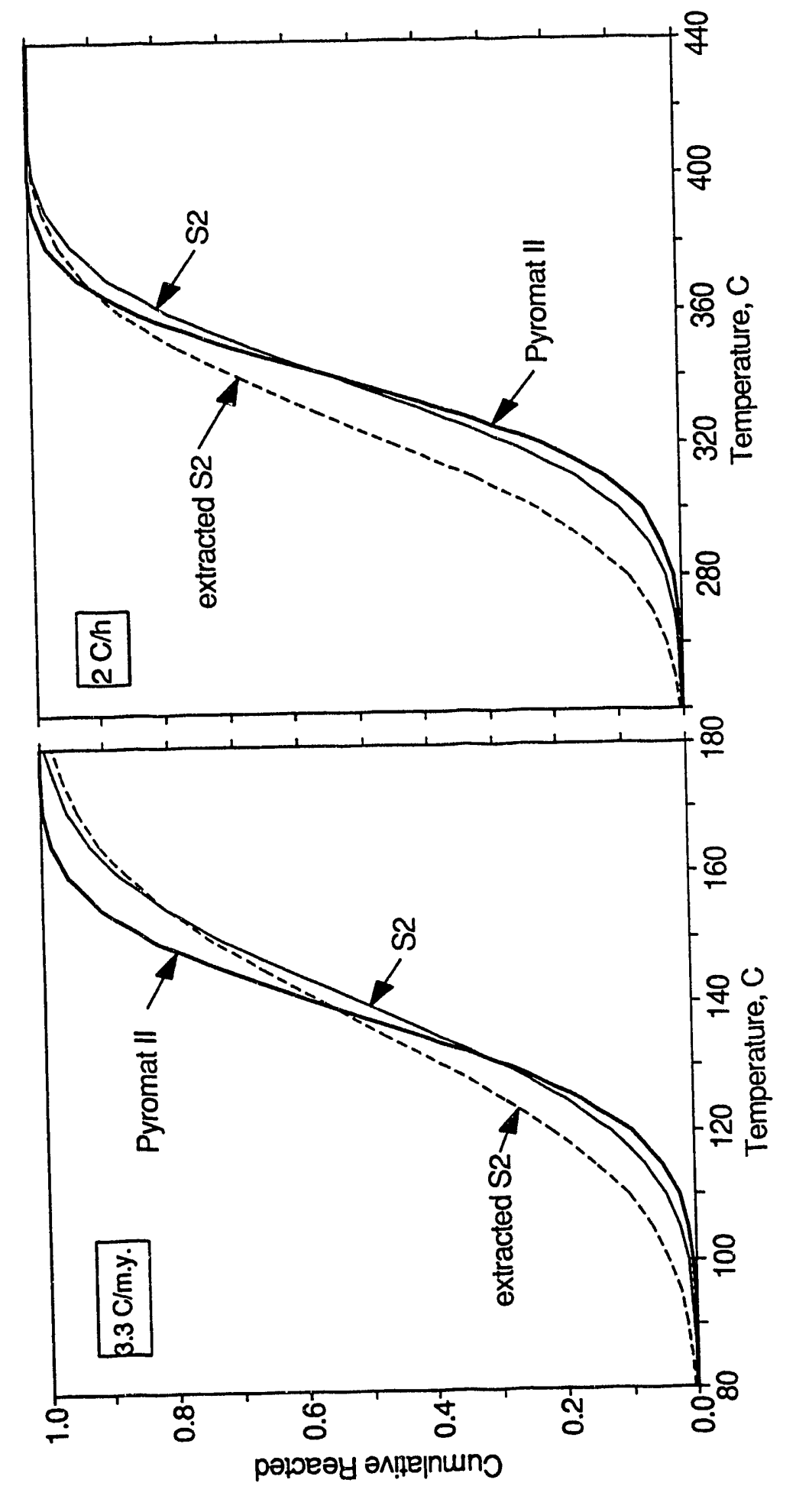

ชั

를

을

홍

ชิ

巳

్ㅗㄴ

.己



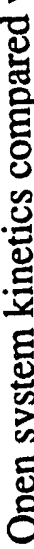

总 
suggests that reliable predictions of geologic maturation require samples in which most of the oxygen has been eliminated naturally. Unfortunately, that makes it impossible to measure the kinetics of early hydrocarbon generation coincident with oxygen elimination.

Because hydrous and high-pressure pyrolysis experiments follow the natural van Krevelan trend more closely, partial maturation of an immature sample under these conditions prior to open-system pyrolysis may produce satisfactory kinetics. Also, it will probably be necessary to introduce some type of serial character into the reaction network in order to properly model both the oxygen elimination and hydrocarbon generation aspects of kerogen maturation.

Acknowledgements. This work was conducted under the auspices of the U.S. Department of Energy by the Lawrence Livermore National Laboratory under contract W-7405-Eng48.

\section{References}

Bar, H., Ikan, R. and Aizenshtat, Z. (1988) J. Anal. Appl. Pyr. 14, 73-79.

Baskin, D. K. and Peters, K. A. (1992) AAPG Bulletin 76, 1-13.

Braun, R. L. and Rothman, A. J. (1975) Fuel 54, 129-131.

Braun, R. L. and A. K. Burnham (1987) Energy \& Fuels 1, 153-161.

Braun, R. L., Burnham, A. K., Reynolds J. G. and Clarkson, J. E. (1991) Energy \& Fuels 5, 192-204.

Burnham, A. K. Pyrolysis Kinetics and Composition for Posidonia Shale (1990) LLNL Report UCRL-ID-105871.

Burnham, A. K. (1991) Energy \& Fuels 5, 205-214.

Burnham, A. K. and Singleton, M. F. (1983) in Geochemistry and Chemistry of Oil Shales, ACS Symp. Ser. 230, F. P. Miknis and J. F. McKay, eds., American Chemical Society, Washington, pp. 335-351.

Burnham, A. K. and Braun, R. L. (1985) In Situ 9, 1-23.

Burnham, A. K. and Braun, R. L. (1990) Org. Geochem. 16, 27-39.

Burnham, A. K. and Dahl, B. (1993) to be presented at the 16th International Organic Geochemistry Meeting, Stavanger, Norway.

Burnham, A. K., Braun, R. L., Gregg, H. R., and Samoun, A. M. (1987) Energy \& Fuels 1, 452-458.

Burnham, A. K., Braun, R. L., Taylor, R. W. and Coburn, T. T. (1989) Preprints ACS Div. Petrol. Chem. 34(1), 36-42.

Burnham, A. K., Oh, M. S., Crawford, R. W. and Samoun, A. M. (1989) Energy \& Fuels 3, 42-55.

Burnham, A. K., Braun, R. L., Sweeney, J. J., Reynolds, J. G., Vallejos, C. and Talukdar, S. (1992) Kinetic Modeling of Petroleum Formation in the Maracaibo Basin: Final Repori, Annex XII, Report DOE/BC/92001051, Avail. NTIS, Springfield, VA. 
Castelli, Chiaramonte, M. A., Beltrame, P. L., Carniti, P., Del Bianco, A. and Stroppa, F. (1990) Org. Geochem. 16, 75-82.

Freund, H., Clouse, J. A. and Otten, G. A. (1992) Preprints, ACS Div. Fuel Chem. 37(4), 1628-1635.

Hubbard, A. B. and Robinson, W. E. (1950) U.S. Bur. Mines, Rept. Inv. 4744.

Hunt, J. M., Lewan, M. D. and Hennet, J.-C. (1991) AAPG Bulletin 75, 795-807.

Jarvie, D. M. (1991) Chem. Geol. 93, 79-99.

Klomp, U. C. and Wright, P. A. (1990) Org. Geochem. 16, 49-60.

Lewan, M. D., Winters, J. C. and McDonald, J. H. (1979) Science 203, 897-899.

Lewan, M. D. (1985) Phil. Trans. R. Soc. Lond. A 315, 123-134.

Lewan, M. D. (1992) Preprints, ACS Div. Fuel Chem. 37(4), 1643-1649.

Marzi, R. (1989) Kinetik und quantitative analyse der isomerisierung und aromatisierung von fossilen steroidkohlenwasserstoffen im experiment und in natürlichen probensequenzen. PhD thesis, Kernforschungsanlage Jülich $\mathrm{GmbH}$, Nr. 2264, Jülich, Germany.

McKee, R. H. and Lyder, E. E., (1912) J. Ind. Eng. Chem. 13, 613-618.

Miknis, F. P., Turner, T. F., Berdan, G. L. and P. J. Conn (1987) Energy \& Fuels 1, 477.

Price, L. C. and Wenger, L. M. (1992) Org. Geochem. 19, 141-159.

Reynolds, J. G. and Burnham, A. K. (1993) Energy \& Fuels, in press.

Schaefer, R. G., Schenk, H. J., Hardelauf, H. and Harms, R. (1990) Org. Geochem. $16115-$ 120.

Schenk, H. J. and Horsfield, B. (1993) Geochim. Cosmochim. Acta 57, 623-630.

Solomon, P. (1992) personal communication.

Sundararaman, P., Merz, P. H. and Mann, R. G. (1992) Energy \& Fuels 6, 793-803.

Sweeney, J. J., Gosnold, W. D., Braun, R. L. and Burnham, A. K. (1992) A Chemical Kinetic Model of Hydrocarbon Generation From the Bakken Formation, Williston Basin, North Dakota, LLNL Report UCRL-ID-112038.

Tissot, B. P., Pelet, R. and Ungerer, P. (1987) AAPG Bulletin 71, 1445-1466.

Wallman, P. H., Tamm, P. W. and Spars, B. G. (1981) in Oil Shale, Tar Sands, and Related Materials, ACS Symp. Ser. 163, H. C. Stauffer, Ed., American Chemical Society, Washington, pp. 93-113.

Ziegel, E. R. and Gorman, J. W. (1980) Technometrics 22, 139. 

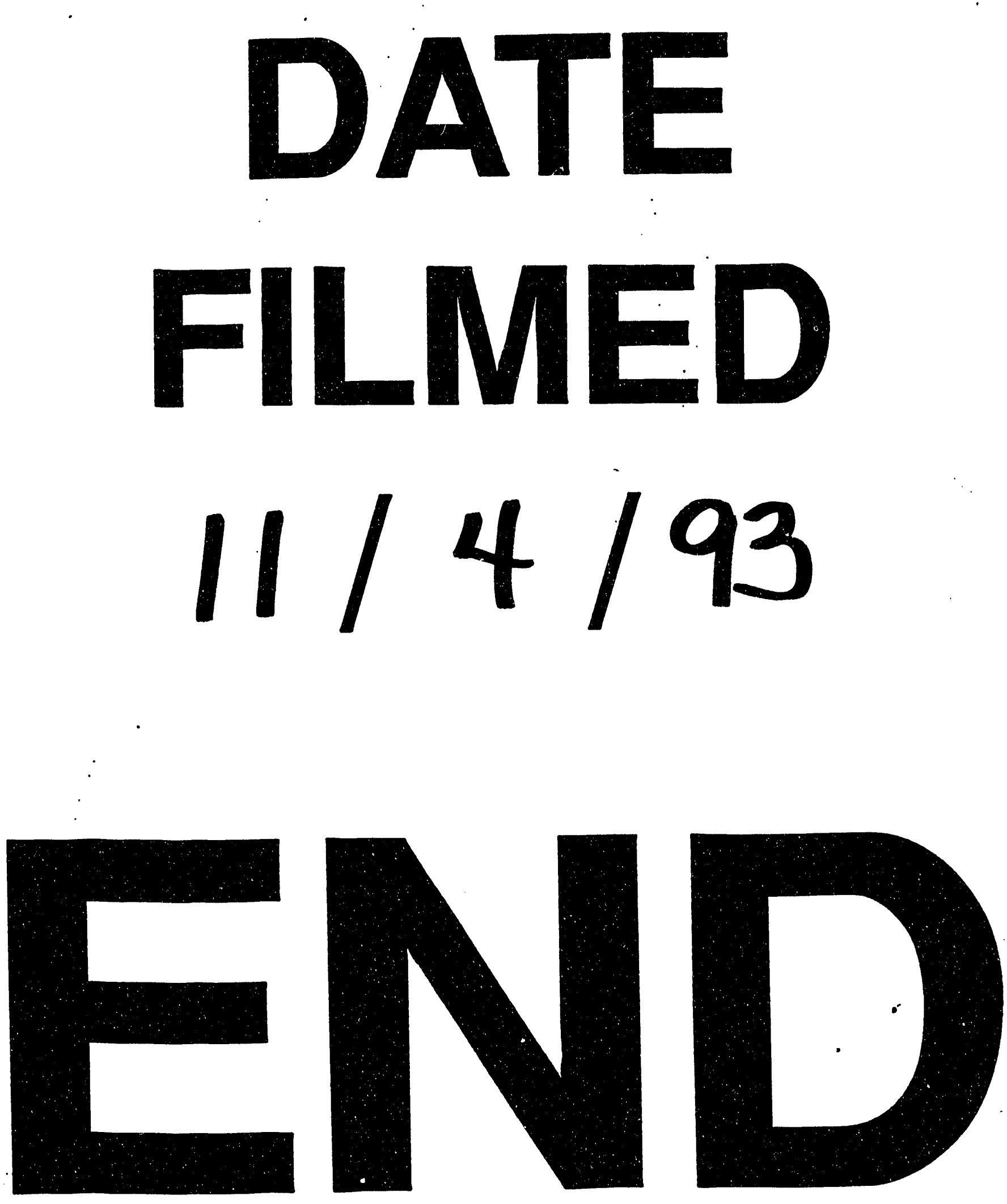
